Article

\title{
Information and Communication Technology-Enhanced Business and Managerial Communication in SMEs in the Czech Republic
}

\author{
Marcel Pikhart *(1) and Blanka Klimova \\ Faculty of Informatics and Management, University of Hradec Kralove, 50003 Hradec Kralove, Czech Republic; \\ blanka.klimova@uhk.cz \\ * Correspondence: marcel.pikhart@uhk.cz
}

Received: 24 May 2020; Accepted: 22 June 2020; Published: 24 June 2020

\begin{abstract}
Current managerial communication in the global business world has recently experienced dramatic and unprecedented changes connected to the use of Information and Communication Technology (ICT) in business and managerial communication. The objective of this paper is to analyze the changes in ICT-enhanced business and managerial communication in Small and Medium Enterprises (SMEs) in the Czech Republic. The use of ICT in business and managerial communication is obvious and brings various benefits, but it also has some drawbacks that should be identified and analyzed. From a methodological point of view, this study is twofold. Firstly, we conduct a systematic review of the current literature on the topic of business and managerial communication, providing an understanding of the recent development in the area of business and managerial communication. Secondly, we conduct qualitative research into the current state of ICT-enhanced managerial and business communication in several SMEs in the Czech Republic. The findings of the literature research show that there are two key aspects that define modern business and managerial communication, i.e., interculturality and interconnectedness. These two aspects of business and managerial communication are very recent, and they bring many challenges that must be considered in order to optimize communication. These altered communication paradigms have the potential to improve global competitiveness and produce new opportunities in the global market. The second part of the research shows that the general awareness of the changes in business communication is limited, and this could potentially pose a threat to business and managerial communication, leading to a loss of opportunities and reduced competitiveness. The majority of global-based companies have already become culture-, communication-, technology- and information-dependent, and ignoring or neglecting this fact presents a significant risk, which may be one of the biggest threats to global competitiveness. Since the success of SMEs is critical for the development of the national economy, it is recommended that company communication be continuously enhanced by frequent training at all organizational levels. This presents a challenge for educational institutions and training centers, managers and businesspeople, of creating communication competencies that would be highly rewarded in the global business environment.
\end{abstract}

Keywords: managerial communication; business communication; electronic communication; intercultural communication; SMEs; applied linguistics; intercultural business communication

\section{Introduction}

In this paper, the business and managerial communication in several Small and Medium Enterprises (SMEs) in the Czech Republic is analyzed, as this area of business communication has still not been researched sufficiently in the Central European context. More specifically, we consider how much 
business and managerial communication is intentionally managed in Czech SMEs and if they take into consideration the very recent changes in the global trajectory of business and managerial communication. The literature review provides us with the most important recent research findings regarding the changes in business and managerial communication. This research is very important, as it provides us with new ideas regarding modern trends in business and managerial communication. The findings of this paper will be crucial both for the Central European (such as Czech, Slovak, Hungarian and Polish) companies who do business globally and also for various educators, such as universities and companies, who provide communication courses for managers.

\section{Fourth Industrial Revolution}

At present, businesses are being influenced by the Fourth Industrial Revolution (Industry 4.0) [1,2], a concept based on the development of fully automated and intelligent production, which enables completely autonomous communication between a company's key players [3]. As Sommer [4] indicates, the technological changes caused by Industry 4.0 will have a profound effect on SMEs as far as communication is concerned. Thus, a company's management must search for an environment that encourages creativity and innovation, and it has to create a clear and open communication system that is applicable within the whole company [5]. Furthermore, effective communication can promote better productivity and maintain strong working relationships, which then results in building trust among employees, contributing to an overall improvement in the company's output and a better competitiveness [6]. The importance of effective business and managerial communication has now been realized all over the world, even in developing countries, which want to succeed in the world's market [7].

Managerial communication, in particular, is the lifeblood of a company and a critical competency for the company's leaders [8]. Recent research indicates that managerial skills are effective at the level of the job satisfaction and job commitment of employees. Therefore, more attention should be paid to the frequency and level of training provided for the development of communication managerial skills [9]. However, nowadays, the influx of rapidly emerging modern technologies creates the novel challenge for managers of exploring new Information and Communication Technology (ICT)-enhanced communication channels for effective communication at all company levels, i.e., both internal and external communication.

\section{Business and Managerial Communication}

Effective communication is especially important in Multinational Enterprises (MNEs), in which both managers and employees come from different geographical and cultural backgrounds, and all employees must use the company's common language, which is usually different from their native one. However, English is used as a lingua franca (ELF), i.e., the shared language of shared business communication, in many contexts. A lot of research has been conducted on how much the use of this communication tool influences all communication processes within the company and also between companies doing business globally [10-14]. By the term, business communication, we understand any communication practices that are used with a business partner to conduct a business case with the aim of profitability, while managerial communication can be understood as a means for leading people within a company. Obviously, while both business and managerial communication have been developing, there have always been issues with them. There are good and bad practices, and each historical era has its own strategies, problems and aims in terms of both business and managerial communication.

\subsection{Interculturality and Interconnectedness}

There are two key aspects of current business and managerial communication that are underway in the global environment, i.e., interculturality and interconnectedness. Intercultural business communication is now crucial for business and managerial communication, as it enables us to be successful communicators in the global intercultural and geographically diverse business environment. 
It is crucial for a company's management to realize that communication in global business companies is affected by the individual culture of the company, such as beliefs, values, norms, morals, myths, and structural elements. Therefore, nowadays, business communication cannot be other than intercultural [15]. The aspects of interculturality also have an impact on the choice of communication tools and, consequently, the outcomes of communication [16]. Not considering the issues of intercultural or cross-cultural communication leads to serious cross-cultural barriers with international partners, customers, distributors and suppliers, which can then result in the termination of business [17].

The second aspect of modern company communication is interconnectedness, i.e., permanent electronic communication connectivity, enabling the participants to be permanently online. A large proportion of communication - if not all communication-in multinational companies is nowadays done virtually via electronic communication. This trend is slowly moving into SMEs as well. It is usually perceived very negatively, because, e.g., hundreds of emails burden employees every day, which has a negative impact on effective communication, especially internally, inside a company due to the loss of time [18]. Thus, it is very important to set clear tasks to perform, the exact time that these tasks will be performed, and other aspects of work organization and communication strategies [19].

\subsection{Global Digital Communication}

The modern communication tools that have emerged recently (i.e., in the past twenty years), such as the Internet and mobile devices, have changed the way people communicate not only in everyday life, but also in business scenarios. They have brought new challenges but also benefits, which must be analyzed so that they can be used more efficiently. As mentioned above, the current business and managerial communication can be defined by two crucial aspects, namely, interconnectedness and interculturality $[20,21]$. What will these mean for the current aspects of business communication? Unprecedented changes in global communication in favor of human-computer interaction have changed the scope and contents of communication patterns significantly, and understanding them will provide businesspeople and managers not only with important tools for communication improvement, but will also be a prerequisite of global competitiveness.

The reality of business organizations is that people need to operate efficiently within these organizations, and communication is a tool that allows one to do so effectively. It is important to realize that traditional communication patterns of business communication [22,23] have been vastly altered, and these changes in communication patterns are ubiquitous in organizations. There are two new forces driving innovation in communication, i.e., the Internet and globalization. Digital organizations, the velocity of changes, and diversity (cultural and mental) present major forces that influence all organizations, their processes, and even company structures. Communication patterns are changing and hence also the ways people work and cooperate with each other. ICT and various mobile devices have had a great impact on the workplace, and modern technology changes the way business is conducted and companies are managed [24].

The digital workplace should, naturally, eliminate the barriers. However, sometimes, the reality is rather the opposite [25]. These digital tools could pose a threat to smooth communication and create a potential space for misunderstanding [26], which could have fatal consequences and be a significant threat to profitability and competitiveness. The current communication is unprecedentedly faster, more information is transferred, and various means of communication channels are chosen for information transfer, including means that did not exist two decades ago. All these aspects can potentially cause distractions, and recent research has proved that things like texting, the use of the Internet in the workplace, smartphone distraction, social media and an increased quantity of emails should be analyzed very carefully, as they are crucial for managerial and business communication and also for a company's internal processes. Naturally, it is not only about analysis, but it is crucial to create clear communication standards in companies, and the setting of these standards will be crucial for maintaining smooth processes within a company and also between companies $[26,27]$. 
Furthermore, business and managerial communication is slowly accepting the new trends, such as the Artificial Intelligence (AI) revolution, biotech and infotech, deep learning, machine learning and other new trends in data science, including the Internet of things (IoT). All these revolutionary technological aspects will cause a lot of sophistication in the workplace, an increased speed of information transfer and, possibly, improved cognitive tools, which can potentially lead to a dramatic paradigm shift towards communication improvement and strategic communication management $[28,29]$. These unprecedented aspects of the current business and managerial communication should be studied properly so as to flag up or eliminate a potential bottleneck, which these modern tools and methods can cause.

\section{Research Methodology}

\subsection{Research Objective}

The purpose of this study is to analyze the changes in business and managerial communication in Czech SMEs and to find out if the management of these companies is aware of these modern changes in communication patterns and also if they have implemented adequate steps toward the improvement of communication. The researched SMEs and their communication strategies and settings were compared with two multinational enterprises, both with well-established communication strategies. These two multinational enterprises were considered as a benchmark and the best practice.

\subsection{Systematic Literature Survey}

This study has two parts. Firstly, in this introductory section, a systematic analysis of the current situation of business and managerial communication is conducted. The first part of the analysis was conducted as literature review in order to show the current situation in the global market in the case of SMEs and how this is reflected in some academic sources, i.e., peer-review journal articles and conference papers written in English.

The key searched collocations were as follows: electronic business AND managerial communication AND SME. The search was conducted in two of the world's acknowledged databases: Web of Science and Scopus. The search was not limited by any time period, because there were not many articles on this topic. Altogether, the authors found 127 journal and conference articles, of which only 23 were suitable for this study, as they fully focused on business communication in SMEs. The other papers generated in these databases with the keywords did not fully focus on communication issues in SMEs. These articles have been referenced in this study. In Figure 1 below, the number of articles detected in Web of Science from 2000 to 2019 is shown. It is revealed that there has been a rising trend in the number of articles, which means that there is a growing interest in this topic. Therefore, this research was conducted to find out if there is any correspondence with an increased interest in the topic of business communication in SMEs as well.

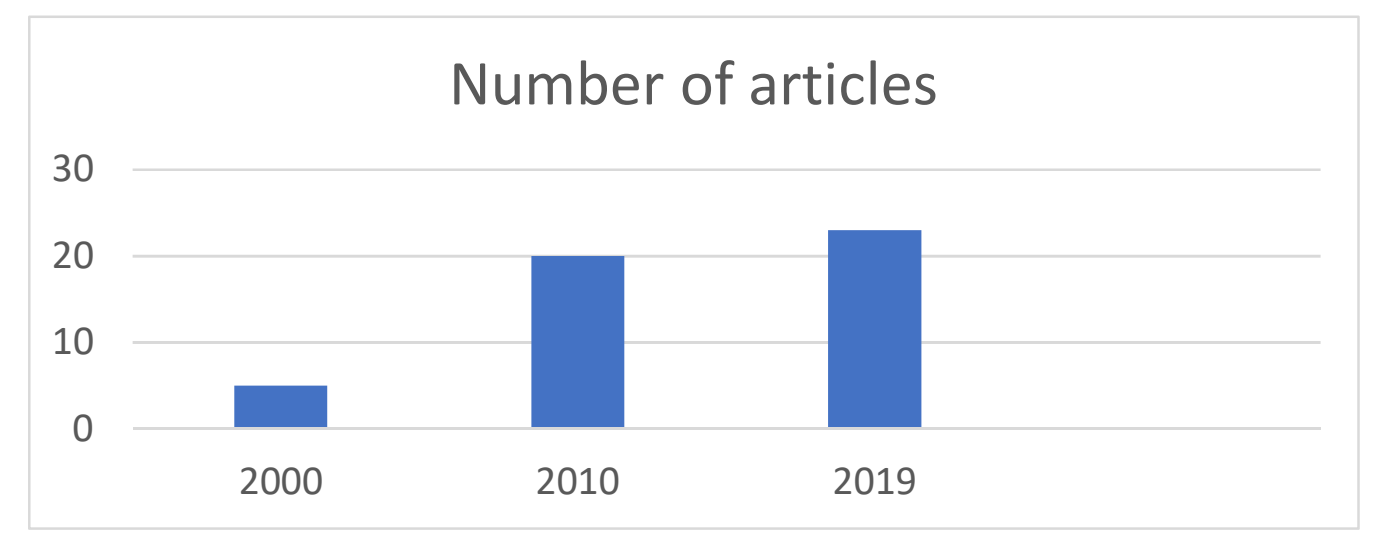

Figure 1. Number of articles detected in Web of Science from 2000 to 2019. 


\subsection{Business Communication in Czech SMEs}

The second part of the research was performed with twenty-four Czech SMEs, which are currently doing business locally in the Czech Republic, but which are also active in the global business market, i.e., all these companies are present in the global market in their business activities. The research was qualitative and in the form of guided interviews with the shareholders of the given twenty-four companies. There were 11 questions during the interview. Each person was interviewed for about half an hour. The answers were recorded and then analyzed using the traditional tools of discourse analysis, such as rewriting the recorded answers and conducting a detailed analysis of the transcripts. The intention of the interviews was to find out to what extent the key employees or owners are interested in and aware of the current situation regarding managerial and business communication and, furthermore, if they are aware of the importance of the intentional management of business and managerial communication.

All the researched companies are regional enterprises based in the Hradec Kralove and Pardubice regions in the eastern part of the Czech Republic, with more than ten but fewer than fifty employees. The interviews were conducted in the second half of 2019 (from August to December 2019). The research focused on the awareness of the changes in business communication patterns in the past few years. The authors of the paper highlighted the fact that the workplace has become digital, the spread of interconnectedness is unprecedented, and the question now is how much the management of these SMEs realized these changes. Moreover, it is crucial to underline that the ability to use modern communication tools and devices is the key to success, as a lot of research has already proven [26,27]. The question is to what extent these new aspects of business communication are implemented in the researched companies.

\subsection{Control Group}

To compare the findings from the researched SMEs, the same research was conducted with a control group of companies functioning as the best practices, namely, two multinational enterprises, which are currently doing business globally, and which have their subsidiaries and branches in the Czech Republic. This control group was used as a comparable parameter, which was utilized as a benchmark for determining how the researched SMEs view the current situation in business and managerial communication and to what extent this communication is managed strategically and intentionally in comparison with the researched multinational enterprises. The reason for choosing these two companies was their geographical closeness to the researched SMEs, i.e., they both have headquarters in the same region as the chosen SMEs.

The research was conducted in the form of interviews using the same questions as those used in the previous group of SMEs. The respondents were the two key employees responsible for the communication strategy in the company on the country level. One company is a major insurance company, and the other one is a leading global manufacturer of electronics components. They are both based in the Pardubice region. The research was conducted, in both companies, in August 2019.

\subsection{Research Question}

The research question is that whether business and managerial communication is managed sufficiently and intentionally in Czech SMEs and whether the management is aware of the importance of intentional communication management. 


\section{Research Results}

The analysis of the literature results clearly shows that the trend regarding the focus on the importance of business and managerial communication and its optimization is very important in the modern business environment. The research question was whether the same trend would be visible in SMEs that are currently doing business in the Czech Republic. Moreover, the most important question was to what extent these trends are reflected in SMEs that are based in the Czech Republic but that are trying to establish a presence globally. Naturally, the trend described in the literature should be reflected in both the MNEs and SMEs. We do not see any reason why there should be differences in the use of modern communication tools in SMEs and MNEs.

Based on the results of the interviews with the management of the researched Czech SMEs, it is clearly visible that neither business nor managerial communication is managed sufficiently and intentionally in these SMEs. The relevant literature is available, the best practices in various MNEs are functional, and different kinds of training opportunities are present as well. However, the management, owners, or the shareholders of these SMEs do not consider a clearly managed communication strategy as very important, and they do not follow intentional strategies to optimize business and managerial communication.

In the following table (Table 1), an overview of the findings of the eleven interview questions is provided. The questions were used as guidelines, and the interviewees were given time and space to provide comments, which were recorded and then analyzed.

Table 1. The research results.

\begin{tabular}{llc}
\hline \multicolumn{1}{c}{ Interview Questions } & MNEs & SMEs \\
\hline 1. Is there a person responsible for the communication strategy in your company? & $100 \%$ & $12.5 \%$ \\
\hline 2. Is there a department responsible for the communication strategy in your company? & $100 \%$ & $8 \%$ \\
\hline 3. Is the management of your company systematically trained in communication? & $100 \%$ & $29 \%$ \\
\hline $\begin{array}{l}\text { 4. Do you think that the interculturality of the global world influences business } \\
\text { communication? }\end{array}$ & $100 \%$ & $16.7 \%$ \\
\hline $\begin{array}{l}\text { 5. Has your company had any kind of communication audit in the past few years? } \\
\text { 6. Are you aware of the fact that electronic communication can negatively influence the } \\
\text { lossless transfer of information? }\end{array}$ & $100 \%$ & $12.5 \%$ \\
\hline \begin{tabular}{l} 
7. Have your employees had any training in how to use modern means of communication? \\
\hline $\begin{array}{l}\text { 8. Has the communication strategy of your company been influenced by modern } \\
\text { communication trends? }\end{array}$
\end{tabular} & $100 \%$ & $54 \%$ \\
\hline $\begin{array}{l}\text { 9. Can you see any drawbacks of electronic means of communication? } \\
\text { 10. Have you ever experienced a situation in the company when the business suffered a loss } \\
\text { due to inefficient communication? }\end{array}$ & $100 \%$ \\
\hline \begin{tabular}{l} 
11. Do you think all front-office employees should be trained in communication strategies? \\
\hline
\end{tabular} & $100 \%$ & $96 \%$ \\
\hline
\end{tabular}

The most important finding of the research is that, in multinational enterprises, an increased interest in the systematic management of communication is very visible and inexorably embodied in all internal communication strategies and processes. However, in SMEs, this trend, based on the research, is still basically non-existent. In the researched MNEs, there are particular employees or even departments responsible for the company's communication strategy, and this trend started a decade ago with the arrival of modern communication tools and alterations to business communication practices, i.e., first, the use of the Internet and, later, the implementation of portable communication devices, namely, smartphones and tablets.

Paperless office strategies have been massively utilized, not only for economic reasons but also because of security or the recent European Union General Data Protection Regulation 2016/679 enforcement. These companies even employ special professionals, who are responsible for the 
maintenance or improvement of the internal communication strategy, i.e., they help with communication patterns, improving the transfer of information within Czech subsidiaries or branches. They are also responsible for the corporate image of a company in the public arena. Moreover, they can facilitate business communication practices when the company is doing business abroad. All these aspects cover the area of business and managerial communication.

The issues of interculturality in business communication are viewed by SMEs as having a very low relevance and importance (see the question 4). This is due to a lack of information. After a discussion with the management of the SMEs, this topic was clarified, and the respondents acknowledged, after giving this topic some thought, that it may have much more relevance and should not be neglected.

In the researched SMEs, the trend is very different from the trends described above in the MNEs. Based on the interviews with the top management of the companies, the owners or shareholders of the SMEs, one can observe that there is rarely any awareness of the importance of a systematic management of both internal and external company communication. The management is not aware of the urgent need to implement some kind of communication audit, which would bring new ideas for improving communication. On the other hand, the MNEs conduct a regular communication audit, which identifies potential risks in communication practices. Obviously, the purpose of this audit is not a mere description of the situation, but it rather suggests improved communication strategies.

The management of the SMEs is aware of the current situation regarding the possible problems associated with using modern tools and devices for business communication, such as smartphones. However, they have not implemented any measures to improve the situation. The reason for this is the lack of information and training possibilities, as expressed by the SME representatives. The MNE employees, on the contrary, receive regular training in communication skills and other soft skills, focusing on practical managerial skills connected to business and managerial communication. This lack of information and training possibilities in SMEs presents a big threat to communication strategies in these companies and can be seen as a big risk that may be negatively influencing the lossless transfer of information within these companies and also between companies, when they are doing business globally or at least trying to establish a global presence.

Basically, all of the SMEs realize the dramatic changes in the past few years, but they are somehow not able to catch up with the modern trends in business and managerial communication. It should also be noted that the reason for their lack of information on how to communicate efficiently is due to their focus on hard skills, even if this trend has already been vastly abandoned in favor of a preference for soft skills and a focus on employees as the most important asset in companies. Naturally, hard skills and company knowhow are crucial for success in production or achieving a high-quality service. However, a lack of soft skills, especially communication skills, will reduce the company's possibilities in the global market. For future development, this situation in SMEs presents one of the biggest threats to global competitiveness and should be taken very seriously.

\section{Discussion}

The findings of this research clearly show that although companies' communication has been significantly changed by the new communication trends, and staff can see the drawbacks of electronic communication, with its negative impact on business, in Czech SMEs, the importance of the intentional management of business and managerial communication is still underestimated. This neglect and the lack of proper management of communication in Czech SMEs has already been highlighted by Holá [27], who also pointed out that attention has mainly been paid to the technical aspects of communication. Obviously, not much has changed since then. However, as Pikhart claims [26], communication barriers can result in significant problems associated with the competitiveness of a company. A company that does not realize the significance of optimized communication, both business and managerial, internal and external, puts itself at risk of a reduced competitiveness in the global market.

As the majority of companies do business globally due to new trends in business processes, the paradigms of interculturality and interconnectedness are present in basically all of them. SMEs and 
MNEs are exposed to new forces that stem from the global nature of business. Transnational and intercultural management is nowadays a commonplace situation, which all companies must adapt to. Companies must attempt to invest in the development of cross-cultural awareness, which can enable more effective information sharing with employees and from employees, as well as among the managers themselves. Kvantaliani and Klimina [30] emphasize the following factors hindering cross-cultural communication: difference in power distance, difference in the degree of uncertainty of avoidance, a lack of a context conducive to communication (high vs. low culture), insufficient knowledge of a common language, technological barriers, and an individual approach to cross-cultural communication [31].

\section{Recommendations}

Several recommendations that could possibly facilitate the communication processes in companies can be drawn from this research. Even if they are not tightly connected to communication, they still influence communication paradigms in companies and are as follows [32]:

- Focusing on specific social attributes, mind patterns and cultural perceptions;

- Researching corporate, societal and hereditary inter-relations and networks;

- Engaging in inter-cultural liaisons in negotiating and mediating agreements;

- Using intra-cultural and inter-cultural stakeholder communication networks;

- Initiating and maintaining cross-cultural business associations;

- Building inter-cultural competence for teams and task forces;

- Providing cultural awareness training and presentations.

Many companies have already implemented conscious communication strategies, and both businesspeople and management have been trained systematically in communication. Many companies have set principles of internal and external communication, taking into consideration the described trends; however, this situation is more or less true only in MNEs, not in SMEs.

As Koudelková [33] states, the success of small and medium SMEs is critical for the development of the Czech economy, and communication, as one of companies' key strategies, should be continuously enhanced by frequent training at all organization levels. This challenge for educational institutions and training centers, managers and businesspeople, is to create communication competencies that are highly rewarded in the global environment. The commodification is not connected to the knowledge of particular languages, as in the past, but it is rather connected to the communication competencies, skills and abilities, thus creating an environment of mutual trust and cooperation [34,35].

In Figure 2, the potential pattern in how to implement a communication strategy improvement is shown in the form of a circle. It starts with an audit of internal communication processes and strategy by a professional company focusing on a deep analysis and evaluation of the company's communication strategy and processes. The results of the audit should be implemented by acknowledging their relevance and informing the employees, which should be followed by communication training for key employees responsible for, or involved in, company communication, i.e., the management, the businesspeople, and the marketing department staff. The following step is the implementation of enhanced communication rules within the company. The employees are also asked to suggest changes in the form of kaizen, i.e., incremental steps, through a bottom-up trajectory. This process should follow a cycle, as it is a permanent qualitative improvement, similar to quality issues in production or service quality. 


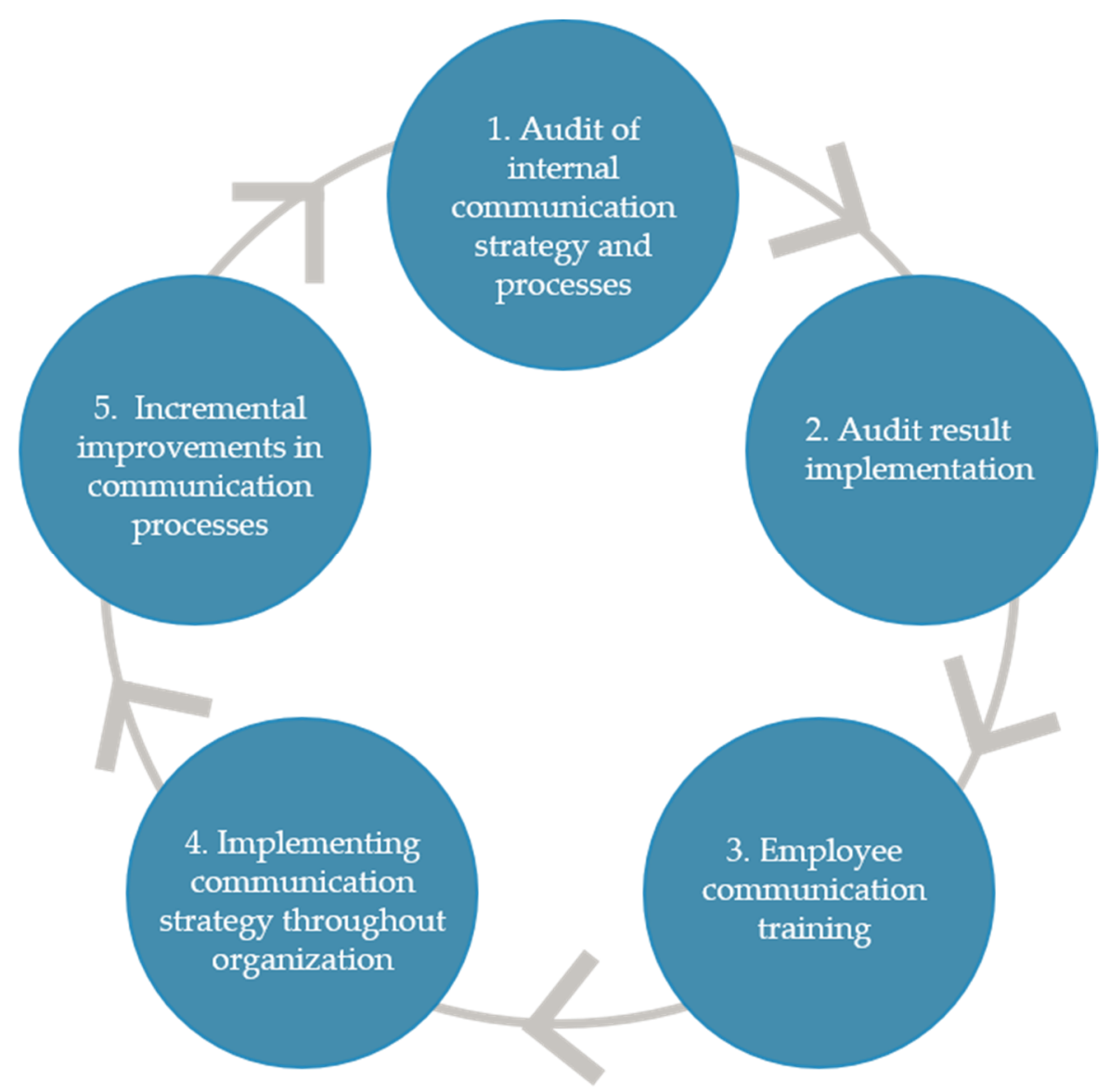

Figure 2. Communication strategy improvement cycle.

\section{Conclusions}

In the present paper, we highlight the importance of the awareness of the dramatic changes in the digital workplace that influence business and managerial communication patterns and strategies. The analyzed literature shows an increased interest in the issues of communication in the workplace, which is influenced by interconnectedness and interculturality. The digital workplace and the velocity of the changes highlight the importance of understanding organizational communication so that companies retain their competitive advantage in the global world.

The research conducted in the Czech Republic shows a limited awareness of the issue in the analyzed SMEs, the owners of which still do not realize that the changes in communication are unprecedented and that critical skills for future leaders will be related to how they communicate in global networks. Moreover, communication in organizations has become one of the most dominant activities, and the need for improved communication is therefore ubiquitous. Organizational efficiency is measurable through its optimized organizational communication patterns-both managerial and business communication. All companies have already become culture-, communication-, technologyand information-dependent, and ignoring this fact presents a significant risk, which is one of the biggest threats to global competitiveness [36].

Obviously, there are limitations to this research, as it was conducted only in the Czech Republic, but the results yielded may be transferable, at least in the context of Central European countries. Further research should be conducted on the current development of business and managerial communication in the larger geographical context. Further research should be focused on business and managerial communication from the perspective of ICT departments, focusing on how they view the situation and what they suggest as possible improvements. 
Author Contributions: Conceptualization, M.P.; methodology, M.P.; formal analysis, M.P., B.K.; investigation, M.P.; resources, M.P., B.K.; writing-original draft preparation, M.P., B.K.; writing-review and editing, M.P. All authors have read and agreed to the published version of the manuscript.

Funding: This research was supported by the SPEV 2104/2020 grant from the Faculty of Informatics and Management, University of Hradec Kralove, Czech Republic.

Acknowledgments: The authors would like to thank Ales Berger for his help with the preparation of the manuscript.

Conflicts of Interest: The authors declare no conflict of interest.

\section{References}

1. Schwaab, K. The Fourth Industrial Revolution; Crown Business: New York, NY, USA, 2017.

2. Reese, B. The Fourth Age: Smart Robots, Conscious Computers, and the Future of Humanity; Atria Books: New York, NY, USA, 2018.

3. Piccarozzi, M.; Aquilani, B.; Gatti, C. Industry 4.0 in Management Studies: A Systematic Literature Review. Sustainability 2018, 10, 3821. [CrossRef]

4. Sommer, L. Industrial Revolution-Industry 4.0: Are German Manufacturing SMEs the First Victims of This Revolution? J. Ind. Engl. Manag. 2015, 8, 1512-1532. [CrossRef]

5. Stacho, Z.; Stachová, K.; Papula, J.; Papulová, Z.; Kohnová, L. Effective Communication in Organizations Increases their Competitiveness. Pol. J. Manag. Stud. 2019, 19, 391-403. [CrossRef]

6. Page, M. The Importance of Good Communication in the Workplace. Retrieved. Available online: https://www.michaelpage.co.uk/advice/management-advice/development-and-retention/importancegood-communication-workplace (accessed on 31 December 2019).

7. Soegoto, E.S. Effective Enterprise Communication and Learning Attitude in Business Performance: A Case Study on SMEs. Eur. Res. Stud. J. 2018, 21, 55-68.

8. Bell, R.L.; Roebuck, D. An Increasing Usefulness for Managerial Communication Research on the Main Topics of Management. J. Manag. Policy Pr. 2015, 16, 71-108. [CrossRef]

9. Paksay, M.; Soyer, F; Calik, F. The Impact of Managerial Communication Skills on the Levels of Job Satisfaction and Job Commitment. J. Hum. Sci. 2017, 14, 642-652. [CrossRef]

10. Bargiela-Chiappini, F. (Ed.) The Handbook of Business Discourse; Edinburgh University Press: Edinburgh, UK, 2009.

11. Bargiela-Chiappini, F. Catherine Nickerson Intercultural Business Communication: A rich field of studies. J. Intercult. Stud. 2003, 24, 3-15. [CrossRef]

12. Chong, B. Why Culture Matters for the Formation of Consumer Trust? A Conceptual Study of Barriers for Realizing Real Global Exchange in Hong Kong. Asia Pac. Manag. Rev. 2003, 8, 217-240.

13. Ihtiyar, A.; Ahmad, F.S. The Role of Intercultural Communication Competence on Service Reliability and Customer Satisfaction. J. Econ. Soc. Stud. 2015, 5, 145-168. [CrossRef]

14. Kei, S.S.; Yazdanifard, R. The Significance of Intercultural Communication for Businesses and the Obstacles that Managers should overcome in Achieving Effective Intercultural Communication. Glob. J. Manag. Bus. Res. Adm. Manag. 2015, 15, 1-6.

15. Brunet-Thorton, R.; Bureš, V. Cross-Cultural Management: Establishing a Czech Benchmark. Ekon. Manag. 2012, 15, 46-62.

16. Hung, S.Y.; Kang, T.C.; Yen, D.; Huang, A.H.; Chen, K. A Cross-Cultural Analysis of Communication Tools and Communication Outcomes. J. Glob. Inf. Manag. 2012, 20, 55-83. [CrossRef]

17. Xu, Z.Y.; Smith, L. Discovering a Solution to SME's Communication Problems: Voicexml Technology, Managing Modern Organizations through Information Technology; IDEA Group Publishing: Harrisburg, PA, USA, 2005.

18. Pikhart, M. Electronic Managerial Communication: New Trends of Intercultural Business Communication. SHS Web Conf. 2017, 37, 714-717.

19. Raulea, C.; Raulea, C. The Impact of Electronic Communication Technology on Teamwork. Latest Trends Comput. 2010, 2, 693-698.

20. Pikhart, M. Aspects of Intercultural Communication in IT: Convergence of Communication and Computing in the Global World of Interconnectedness. In Advanced Multimedia and Ubiquitous Engineering; Springer: Singapore, 2020; Volume 590, pp. 251-256. 
21. Pikhart, M.; Koblížková, A. The Central Role of Politeness in Business Communication: The Appropriateness Principle as the Way to Enhance Business Communication Efficiency. J. Intercult. Commun. 2017, 45, 1-21.

22. Ball, D.A.; Mcculloch, W.H. International Business: The Challenge of Global Competition; McGraw-Hill Irwin: New York, NY, USA, 1996.

23. Bartlett, C.; Beamish, P. Transnational Management. Text, Cases, and Readings in Cross-Border Management; McGraw-Hill Irwin: New York, NY, USA, 2008.

24. Harris, T.E.; Nelson, M.D. Applied Organizational Communication. Theory and Practice in a Global Environment; Routledge: New York, NY, USA; London, UK, 2019.

25. Buckland, M. Information and Society; MIT Press: Cambridge, MA, USA, 2017.

26. Pikhart, M.; Holá, J. The Implementation of Internal Communication System as a Way to Company Efficiency. Ekon. A Manag. 2014, 2, 161-169.

27. Holá, J. Internal Communication in the Small and Medium Sized Enterprises. Ekon. A Manag. 2012, 15, $32-45$.

28. Hofkirchner, W. Intelligence, Artificial Intelligence and Wisdom in the Global Sustainable Information Society. Proceedings 2020, 47, 39. [CrossRef]

29. Masri, N.W.; You, J.-J.; Ruangkanjanases, A.; Chen, S.-C.; Pan, C.-I. Assessing the Effects of Information System Quality and Relationship Quality on Continuance Intention in E-Tourism. Int. J. Environ. Res. Public Health 2020, 17, 174. [CrossRef]

30. Kvantaliani, M.; Klimina, O. Implications of Cross-Cultural Communication in Business: A Study of Swedish Small Enterprise "Imsevimse" and Its International Distributors and Retailers. Retrieved. Available online: http://www.diva-portal.org/smash/get/diva2:421545/fulltext02 (accessed on 31 December 2019).

31. Hofstede, G. Cultural Dimensions in Management and Planning. Asia Pac. J. Manag. 1984, 1, 81-99. [CrossRef]

32. SBC International. Cross-cultural Business Communication for SMEs. Available online: https://www.sbcinternational.de/expertise/communications-cross-cultural-liaison/sme-cross-cultural-business-communication/ (accessed on 31 December 2019).

33. Koudelková, P. Innovation in Small and Medium Enterprises in the Czech Republic. Cent. Eur. Bus. Rev. 2014, 3, 31-37. [CrossRef]

34. Chua, R.Y.J.; Morris, M.W.; Mor, S. Collaborating across Cultures: Cultural Metacognition E Affect-Based Trust in Creative Collaboration; Harvard Business School: Boston, MA, USA, 2012.

35. Ng, E.S.; Waheeda, L. Intercultural Communication in the World of Business. In Intercultural Communication Handbooks of Communication Science; Chen, L., Ed.; De Gruyter Mouton: Berlin, Germany, 2017; pp. 597-616.

36. Odine, M. Communication problems in management. J. Emerg. Issues Econ. Financ. Bank. (JEIEFB) 2015, 4, $1615-1630$.

(C) 2020 by the authors. Licensee MDPI, Basel, Switzerland. This article is an open access article distributed under the terms and conditions of the Creative Commons Attribution (CC BY) license (http://creativecommons.org/licenses/by/4.0/). 